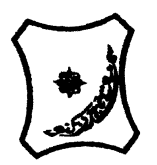

Bayero Journal of Pure and Applied Sciences, 13(1); 14 - 19

Received: April, 2020

Accepted: June, 2020

ISSN $2006-6996$

\title{
EFFECTS OF STORAGE OF Moringa oleifera SEED POWDER ON TURBIDITY REMOVAL FROM MEDIUM TURBID WATER
}

\author{
Salisu, A. D. ${ }^{1}$ and Mohammed, K. ${ }^{2} *$ \\ ${ }^{1}$ Department of Civil Engineering Technology, Federal Polytechnic, Bauchi, Nigeria \\ ${ }^{2}$ Department of Civil Engineering, Bayero University, Kano, Nigeria \\ *Corresponding author: kmohammed.civ@buk.edu.ng
}

\begin{abstract}
Processed Moringa oleifera seeds are used as one of the alternative natural coagulants for turbidity removal from surface water. This paper investigated the influence of storage of M. oleifera seed powder on its turbidity removal from river water. M. oleifera seed powder stored indoors and outdoors each from 0 to 6 months were used to treat river water of medium turbidity (30 to $104 \mathrm{NTU}$ ). Three stock solutions of M. oleifera seed powder (i.e. $0.2,0.4$, and $0.6 \% \mathrm{w} / \mathrm{V}$ ) were used to conduct Jar test on the water samples. M. oleifera seed powder stored indoors and outdoors attained excellent turbidity removal with efficiency ranging from 92 to $100 \%$ at coagulant dose ranging from 320 to $2400 \mathrm{mg} / \mathrm{L}$ with $\mathrm{pH}$ of the treated water ranging from about 7 to 8 . M. oleifera seed powder can be prepared and stored for 3 to 6 months from harvest while still achieving very good turbidity removal efficiency.
\end{abstract}

Keywords: Medium turbidity; Moringa oleifera seed; raw water; storage; turbidity removal.

\section{INTRODUCTION}

Water is a basic human need and lack of access to clean potable water is a major cause of water-related diseases in low-income countries. The quality and quantity of water used for households is an important aspect of domestic water supplies, which influences personal hygiene and public health. Water of improved quality is usually obtained by treating raw water to improve clarity, taste and odour, or to remove harmful organisms (Egbuikwem and Sangodoyin, 2013; Guy and Jamie, 2003).

Despite the remarkable improvement achieved in the provision and access to safe drinkingwater over the past decades in many parts of the world, approximately one billion people still lack access to clean water (Guy and Jamie, 2003). Developing countries face potable water supply problems because of inadequate financial resources. The cost of water treatment is increasing and the quality of river water is not stable due to turbidity caused by suspended and colloidal particles resulting from surface runoff into surface water bodies during or after rainfall. In some tropical developing countries, clarification of turbid river water using locallyavailable plant-based materials as coagulants is an ancient and common practice. Of the many plant materials investigated, seeds of Moringa oleifera is one of the effective sources of coagulant for water treatment (see Varkey, 2020; Okuda and Ali, 2019; Halkade and Pise, 2013), containing active agents with good coagulation ability. The extract of the seed has been used to remove hardness from water (Muyibi and Evison, 1995).

Abaliwano et al., (2008) reported that $M$. oleifera seed is an effective coagulant comparable to the much used synthetic chemical coagulants such as aluminium and iron salts.

Therefore, this study investigated the influence of storing $M$. oleifera seed powder on turbidity removal from river water with a view to obtaining optimum coagulation dose for certain storage period within 6 months.

\section{MATERIALS AND METHODS}

Moringa oleifera Seed Powder Preparation M. oleifera seeds were procured from "MudaLawan" market, Bauchi City in northeast Nigeria. The seeds were de-husked manually with the aid of mortar and pestle; the clean kernels were then milled into fine powder with the aid of a manual grinding machine, the powder was sieved through $210 \mu \mathrm{m}$ BS sieve as described by Bichi (2013); Alo et al. (2012) and Bichi et al. (2012).

Defatting by Soxhlet Extraction

Soxhlet extraction method was used to defat oil from $200 \mathrm{~g}$ of $M$. oleifera seed powder using electro-thermal (heating mantle, model MG3868) using $\mathrm{n}$-Hexane as the extracting solvent. 
BAJOPAS Volume 13 Number 1, June, 2020

The extracted powder was air-dried for $24 \mathrm{~h}$ to allow n-Hexane to evaporate and then $164 \mathrm{~g}$ was obtained.

\section{Storage of the Prepared Powder}

The defatted $M$. oleifera seed powder was divided into two potions; each portion was packaged and sealed in a separate polythene bag. The first package was stored in the Laboratory and labeled "indoor storage", while the second package placed at a weather station outside and labeled "outdoor storage". The Laboratory and weather station with coordinate $10.418754,9.880764$ are sited at the water treatment plant near Gubi Dam, about $14 \mathrm{~km}$ north of Bauchi City. The Laboratory provides water quality analyses to Bauchi State Water Board. See Wufem et al. (2009) for more details on Gubi Dam.

The prepared powders were stored under conditions mentioned earlier between February and June, 2016. Temperature, pressure, humidity, rainfall, and wind speed ranged from 19 to $41{ }^{\circ} \mathrm{C}, 752$ to $764 \mathrm{mmHg}, 7$ to $79 \%, 0$ to $7.6 \mathrm{~mm}$, and 0 to $11 \mathrm{~m} / \mathrm{s}$, respectively. These meteorological information was obtained from the daily record of the above parameters at the weather station.

\section{Coagulant Stock Solution}

Stock solution of $M$. oleifera seed powder was prepared by placing 2, 4, and $6 \mathrm{~g}$ each of the seed powder into conical flaks I with each flask containing $100 \mathrm{~mL}$ of distilled water. The mixture in each flask was shaken three times (for 2 mins each) at intervals of 5 mins for proper dissolution of the powder to obtain 0.2 , 0.4 and $0.6 \% \mathrm{w} / \mathrm{v}$ stock solution, respectively. The solutions were then filtered using muslin cloth (Hitendra et al., 2012; Katayon et al., 2006).

\section{Collection of Raw River Water}

Medium turbid raw water sample with turbidity ranging from 30 to 104 NTU was collected on each experiment day in a $15 \mathrm{~L}$ sterilized plastic container (as specified by Katayon et al., 2004) from a stream tributary located around Gubi village. The stream supplies water to villages downstream of the Gubi Dam that have no access to municipal water supply. A photometer (Model 7100, Palintest, England) was used to measure the turbidity level of the raw water in duplicates.

\section{Coagulant Dose}

Four $1 \mathrm{~L}$ capacity beakers were filled with the turbid raw water sample to $250 \mathrm{~mL}$ mark. A portion of the prepared $0.2 \mathrm{w} / \mathrm{v}$ stock solution (i.e. $40,60,80$ and $100 \mathrm{~mL}$ ) was added to raw water to obtain mass concentration of 320 , 640, 960 and $1280 \mathrm{mg} / \mathrm{L}$, respectively. This procedure was repeated for the 0.4 and $0.6 \%$ w/v stock solutions, respectively.

\section{Jar Test}

Dose optimization was carried out using jar test apparatus according to Ndabigengesere et al., (1995). About $500 \mathrm{~mL}$ of the raw water was added into each of six $1 \mathrm{~L}$ capacity beakers each having one of the coagulant doses presented earlier. The beakers were stirred at $100 \mathrm{rpm}$ for 2 mins. The speed was then reduced to $25 \mathrm{rpm}$ and the mixing continued for 20 mins. The samples were then allowed to settle for about 30 mins. After settling, supernatant samples were collected from each beaker and tested for residual turbidity. The optimum dose of the $M$. oleifera seed powder was that of the sample with the least amount of residual turbidity after carrying out the Jar test.

\section{Statistical Analysis}

One-way analysis of variance (ANOVA) was employed to test the significance of variation of turbidity removal efficiency and $\mathrm{pH}$ between storage durations and conditions using Data Analysis in Microsoft Excel 2013.

\section{RESULTS AND DISCUSSION \\ Effect of Storage Condition on Performance of M. oleifera Seed Powder}

Coagulation of medium turbid water with $M$. oleifera seed powder extract $0.2,0.4$ and $0.6 \% \mathrm{w} / \mathrm{v}$ resulted in turbidity removal efficiency ranging from about 93 to $100 \%$ and 92 to $100 \%$ under indoors and outdoors storage conditions, respectively, for the duration of 0,3 and 6 months (denoted as t0, t3 and t6; Figures 1 and 2). The $M$. oleifera powder stored indoors achieved slightly higher turbidity removal efficiency than that stored outdoors. This might be due to direct impact of environmental effects on the powder as previously reported by Katayon et al. (2004). 


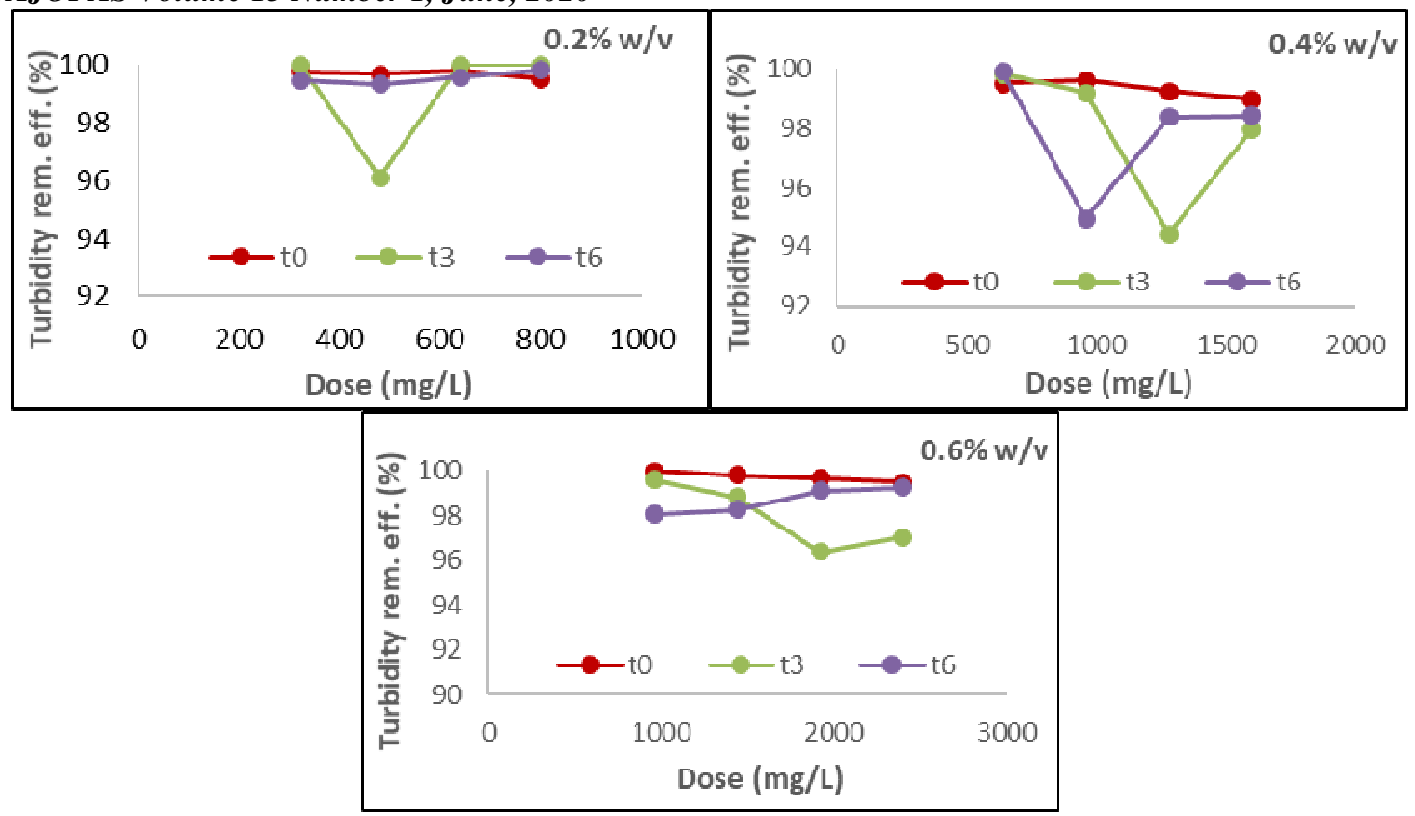

Figure 1: Turbidity removal efficiency of $M$. oleifera seed powder stored indoors for 0,3 and 6 months.

\section{Effect of Storage Duration of M. oleifera Seed Powder on Turbidity Removal} With respect to storage duration, the turbidity removal efficiencies of the $M$. oleifera powder at $0.2,0.4$ and $0.6 \% \mathrm{w} / \mathrm{v}$ ranged from 97.7 to $99.7 \%, 94.3$ to $99.5 \%$, and 93.2 to $100 \%$ at the start, after 3 and 6 months, respectively (Figure 2).

Lowest turbidity removal efficiencies were obtained at 3 months storage whereas highest values (i.e. $100 \%$ at $0.2 \% \mathrm{w} / \mathrm{v}$ in Figure 1 ) were recorded at the beginning of the storage duration. One-way analysis of variance (ANOVA) conducted on the turbidity removal efficiencies of $0.2,0.4$ and $0.6 \% \mathrm{w} / \mathrm{v}$ seed powder stored indoors and outdoors revealed no significant and significant difference, respectively, across storage durations (with respective mean $p$ - values $=0.44$ and 0.02 , at $a=0.05$ ).

Similar findings were reported by Noor et al., (2012) while investigating the coagulating ability of spray-dried salt-extracted $M$. oleifera seeds powder under different storage conditions. Interestingly, 6-month storage achieved higher turbidity removal efficiencies than 3-month with almost similar removal efficiencies between the freshly prepared and 6-month stored seed powders at some points, regardless of storage condition (see Figures 1 and 2).

This trend may possibly be due to disintegration and formation of active ingredients after about 3 and 6 months, respectively, resulting in improved turbidity removal efficiency after 6 months of storage. The turbidity removal efficiency found in this study are similar to those reported by Noor et al. (2012). 


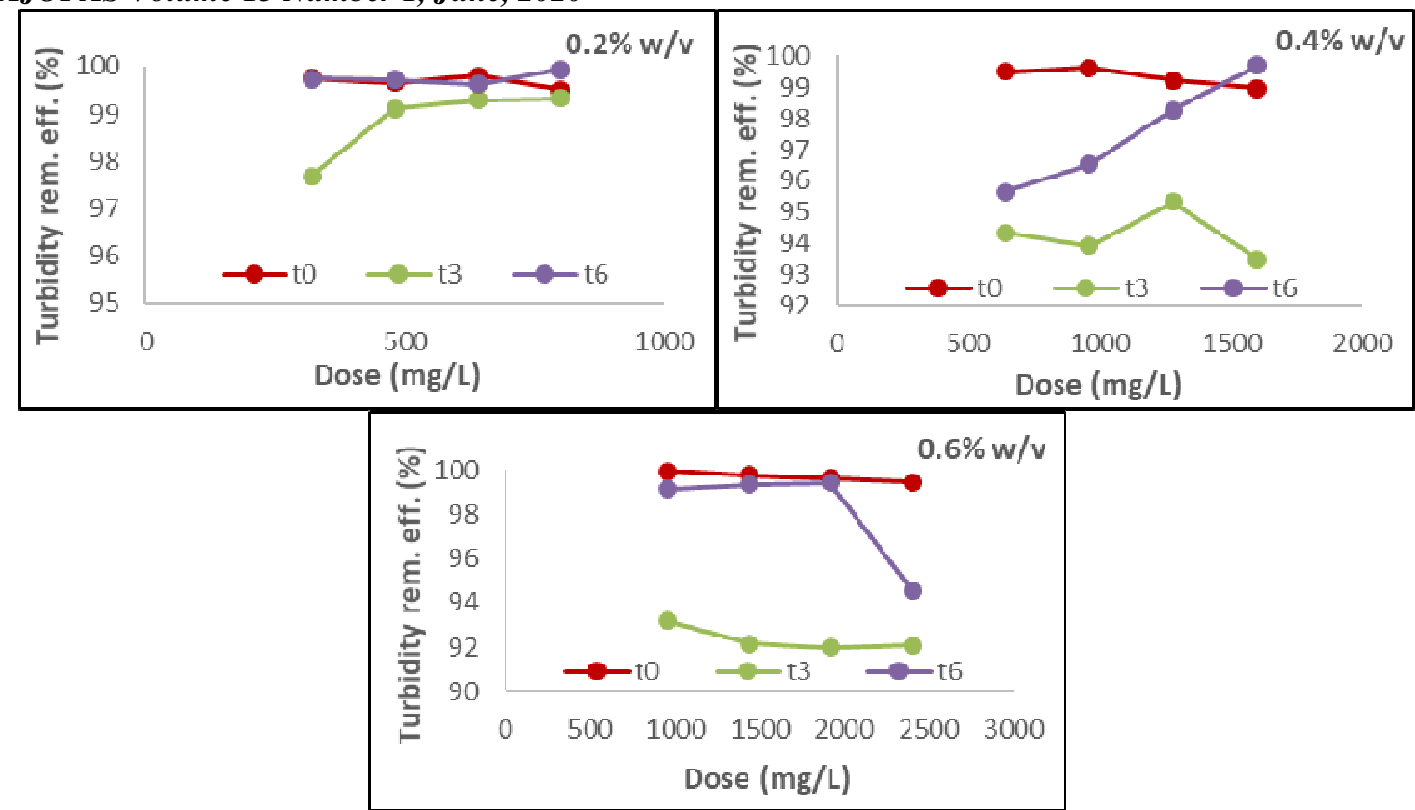

Figure 2: Turbidity removal efficiency of $M$. oleifera seed powder stored outdoors for 0 , 3 and 6 months

Effect of Storage Condition and Duration on pH of M. oleifera Seed Extract

The $\mathrm{pH}$ values of the extract obtained from the indoor- and outdoor-stored $M$. oleifera seed powder are shown in Figures 3 and 4. The $\mathrm{pH}$ ranged from 7.7 to $9.3,7.4$ to 7.9 and 7.4 to 7.7 at $0.2,0.4$ and $0.6 \% \mathrm{w} / \mathrm{v}$ of the $M$. oleifera seed extract, respectively.

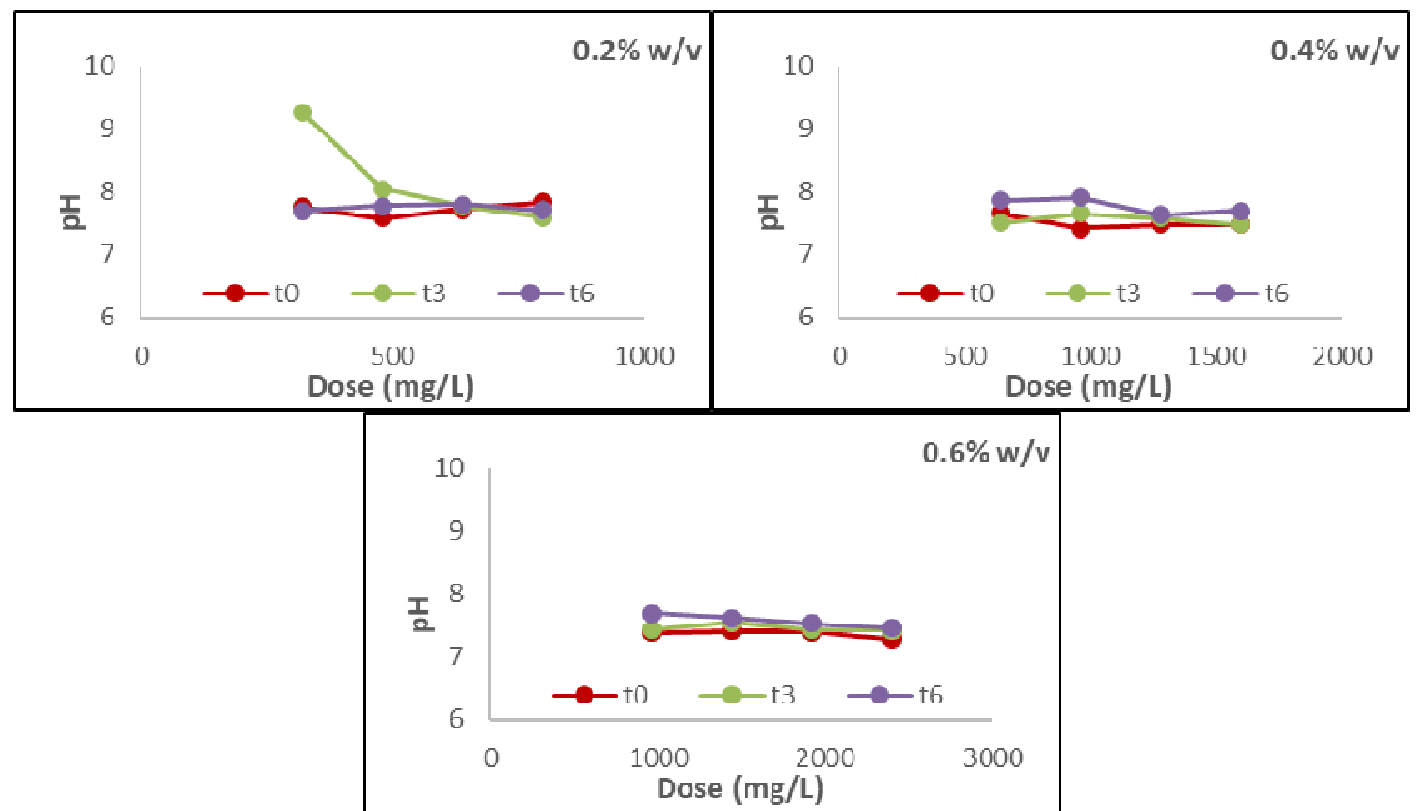

Figure 3: Variation of $\mathrm{pH}$ with dose of $M$. oleifera seed powder stored indoors for 0,3 and 6 months.

All of the coagulation $\mathrm{pH}$ values fall within the drinking-water range of 6.5 to 8.5 recommended by WHO (2011) regardless of storage condition except for $0.2 \% \mathrm{w} / \mathrm{v}$ stored for 3 months, appearing to be an outlier. Noteworthy, $\mathrm{pH}$ values ranging from 6.95 to 7.84 were obtained when the seed powder was stored outdoors. These values are generally lower than those obtained with indoor storage. As expected, the treated water does not require $\mathrm{pH}$ adjustment before consumption, after satisfying other drinking-water quality characteristics. 


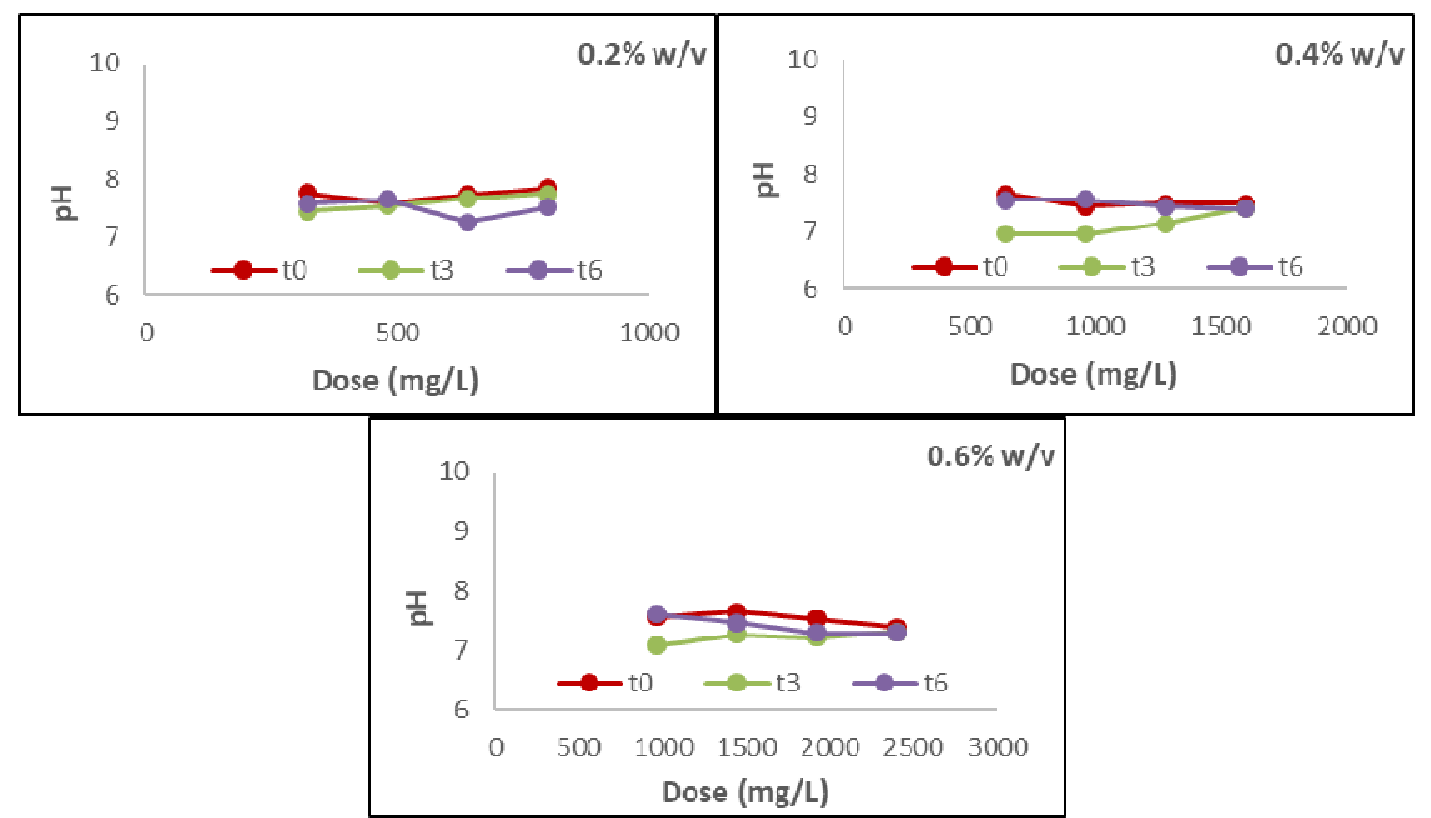

Figure 4: Variation of $\mathrm{pH}$ with coagulant dose of $M$. oleifera seed powder stored outdoors for 0,3 and 6 months.

One-way ANOVA conducted on the $\mathrm{pH}$ values of the $M$. oleifera seed extracts at 0.4 and $0.6 \%$ $\mathrm{w} / \mathrm{v}$ revealed significant difference across storage durations, regardless of storage conditions (mean $p$-value $=0.01$ at $a=0.05$ ). However, the $\mathrm{pH}$ values of the seed powder at $0.2 \% \mathrm{w} / \mathrm{v}$ were not significantly different (mean $p$-value $=0.26$ at $a=0.05)$.

\section{CONCLUSION}

Extract of Moringa oleifera seed powder excellently removed turbidity from river water of medium turbidity with removal efficiency ranging from 92 to $100 \%$ under indoor and outdoor storage conditions. There was no significant difference in turbidity removal efficiency with the

\section{REFERENCES}

Abaliwano, J. K., Gbebremichael, K. A., and Amy, G. L. (2008). Application of the Purified Moringa Coagulant for Surface Water Treatment. Institute for Water Education. Netherlands: Water Mill.

Alo, M.N., Anyim, C., and Elom, M. (2012). Coagulation and Antimicrobial Activities of Moringa oleifera Seed Storage at $3^{\circ} \mathrm{C}$ Temperature in Turbid Water. Advances in Applied Science Research, 887-894.

Bichi, M.H. (2013). A Review of the Applications of Moringa oleifera Seeds Extract in Water Treatment. Civil and Environmental Research, 1-10.

Bichi, M.H., Agunwamba, J.C., and Muyibi, S.A. (2012). Optimization of Operating Conditions for the Application of Moringa oleifera Seeds extract in Water powder stored indoors from 0 to 6 months. However, there was significant difference in turbidity removal efficiency with the powder stored outdoors for the same duration.

The $\mathrm{pH}$ of the treated water varied significantly at or above $0.4 \% \mathrm{w} / \mathrm{v} M$. oleifera seed extract concentration, with values mostly within the drinking-water range of 6.5 to 8.5. Therefore, $M$. oleifera seed powder can be prepared and stored for 3 to 6 months from harvest while still achieving very good turbidity removal efficiency. Effects of storage conditions on M. oleifera seed powder on turbidity removal efficiency using other extraction techniques such as spray-drying and salt extraction may require further studies.

Disinfection Using Response Surface. African Journal of Biotechnology, 1587515887.

Egbuikwem, P., and Sangodoyin, A.Y. (2013). Coagulation Efficacy of Moringa oleifera Seed Extract Compared to Alum for Removal of Turbidity and E. coli in Three Different Water Sources. European International Journal of Science and Technology, 13-20.

Guy, H., and Jamie, B. (2003). Domestic Water Quantity, Service Level and Health. Geneva, Switzerland: WHO Document Production Services.

Halkade, D.S., and Pise, C.P. (2013). Factors Affecting the Coagulation of Turbid Water with Blend Coagulant Moringa oleifera and Alum, International Journal 
BAJOPAS Volume 13 Number 1, June, 2020 of Advanced Research in Engineering and Technology, 181-190.

Hitendra, B., Folkard, G., and Sanjeev, C. (2007). Innovative physico-chemical treatment of wastewater incorporating Moringa oleifera seed coagulant, Journal of Hazard Materials., 142(1-2): 477 82.

Katayon, S., Megat, M.N., Asma, M., Thamer, A.M., Abdullahi, L.A., Idris, A., Suleyman, A.M., Aminuddin, M.B., and Khor, B.C. (2004). Effects of Storage Duration and Temperature of Moringa oleifera Stock Solution on its Performance in Coagulation. International Journal of Engineering and Technology, 146-151.

Katayon, S., Ng, S.C., Megat, J.M., and Abdul, G. L. (2006). Preservation of coagulation efficiency of Moringa oleifera, a natural coagulant. Biotechnology and Bioprocess Engineering, 489-485.

Muyibi, S.A., and Evison, L.M. (1995). Moringa oleifera Seeds for Softening Hardwater, Water Research, 29(4): 1099-1104.

Noor M.J.M.M, Ezzuldin, H.M., and Thamer, A.M. (2012). Effect of the packaging and storage conditions on the coagulation activity of spray-dried salt-extracted Moringa oleifera. Desalination and Water Treatment, 1-7.

Ndabigengesere, A., Narasiah, K.S., and Talbot, B.G. (1995) Active Agents and Mechanism of Coagulation of Turbid Waters using Moringa oleifera. Water Research 29(2): 703-710.

Okuda T. and Ali E.N. (2019) Application of Moringa oleifera Plant in Water Treatment. In: Bui XT., Chiemchaisri C., Fujioka T., Varjani S. (eds) Water and Wastewater Treatment Technologies. Energy, Environment, and Sustainability. Springer, Singapore

Varkey, A.J. (2020) "Purification of River Water Using Moringa Oleifera Seed and Copper for Point-of-Use Household Application." Scientific African, 8: e00364.

World Health Organisation (2011) Guidelines for Drinking-water Quality. 4th ed., WHO, Geneva.

Wufem, B.M., Ibrahim, A.Q, Gin, N.S., Shibdawa, M.A., Adamu, H.M. and Agya, P.J. (2009), Level of Heavy Metals in Gubi Dam Water, Bauchi, Nigeria, Global Journal of Environmental Sciences, 8(2): 29-37. 